\title{
Student Perspectives on the Use of iPads for Navigating Construction Draw- ings: A Case Study
}

\section{Dr. Tom Michael Leathem, Auburn University}

Tom Leathem is an Assistant Professor in the McWhorter School of Building Science at Auburn University where he teaches courses in Estimating, Construction Documents, Scheduling, and Project Delivery. He has 11 years industry experience in commercial construction management, holds a Ph.D. in Education, an M.S. in Integrated Design \& Construction, and a B.S. in Construction Management. His areas of research include construction education, assessment, accreditation, instructional technology, and active learning.

\section{Prof. Lauren W Redden, Auburn University}

Lauren Redden holds a Masters degree in Building Construction from Auburn University. Her industry experience includes working in Pre-Construction Services as an Estimator, and working in various positions in Operations including Project Management and Quality Control/Assurance. She is currently a Tenure Track Assistant Professor with the McWhorter School of Building Science at Auburn University. Her research interests center around construction education, mobile technologies, service learning, and historically significant construction events throughout the world. She has published in several conferences proceedings. Contact Information: 118 M. Miller Gorrie Center, Auburn, AL 36849, USA. Phone: 334.844.5341. Email: wybenlm@auburn.edu

\section{Mr. Jeffrey Kim, Auburn University}

Dr. Wesley Collins, Auburn University

Wesley Collins is an assistant professor in the McWhorter School of Building Science at Auburn University. Dr. Collins completed his PhD in Construction Management at Arizona State University in 2015, and was awarded the Outstanding CII Graduate Research Assistant Award from the Construction Industry Institute for his doctoral research. Dr. Collins has over 15 years of experience as a construction professional and academic. He spent his professional career working as an estimator and project manager, managing a variety of projects across the United States. As an academic, he has published papers at national and international conferences, and in academic journals.

\section{Mr. Ishmael Boynton Preer}




\section{Student Perspectives on the use of iPads for Navigating Construction Drawings: A Case Study}

\section{Introduction}

The rate of educational technology integration continues to increase as faculty become more agreeable to the positive impact that it has on student learning [1]. Pilgrim, Bledsoe \& Reily (2012) [2] in their research, New Technologies in the Classroom state that "integrating technology into instruction means students are utilizing technology to enhance higher-level thinking skills and problem-solving". Consequently, an approach toward active learning would be supported by the use of more technology. Likewise, computing technology and the Internet have, and will continue to have, profound effects on the construction process [3]. Processes involving building information modeling (BIM), laser scanning, drones, virtual reality, and mobile devices are just some of the technologies that are currently revolutionizing the industry [3].

The ways by which the industry uses technology should be "mimicked" [4] in academia if faculty are to prepare the future practitioners in the industry. Students are limited by their lack of experience in the application of new technologies in the construction industry [5]. Furthermore, students are often unable to connect the use of technology to a learning experience [6], therefore, instructors must be willing and able to make those connections for them. Construction faculty must seek ways to actively engage Generation Z students [7] in ways that these tech-savvy students prefer to learn. Unfortunately, construction academics continue to struggle to define a clear path regarding how technology can be used in the classroom [4] which could be a detriment to the learning experience [8]. Moreover, the utilization of technology in a construction management classroom can be cumbersome if there is not a well-thought-out plan to do so, and the instructor is not aware of the impacts (good or bad) of introducing new technology.

The incorporation of one ubiquitous technology, mobile devices, into construction management coursework shows much promise $[9,10,11]$. However, the literature only provides two specific examples of how mobile devices have actually been incorporated [5,12]. Reyes et al. (2015) [5] describe the incorporation of iPads into an undergraduate blueprint reading course, and found that students were more efficient in completing the class exercise when able to familiarize themselves with a hard set of blueprints ahead of working with the blueprints on a mobile device. Cline and Davis (2013) [12] describe the integration of iPads into a construction materials and methods laboratory course. They stated that the incorporation of iPads (1) facilitated communications between the student and the instructor, (2) increased the student's construction safety knowledge, (3) increased the student's communication and problem-solving skills, all while providing the students with experience utilizing technology that they is commonly used in industry.

Neither of the aforementioned studies that provided specific examples of incorporation $[5,12]$ researched the student's perspectives regarding the effort necessary to complete learning tasks through different technological modalities. The National Aeronautics and Space Administration Task Load Index (NASA-TLX) tool is one such method of measuring expended effort and perceived performance (i.e., workload) when completing a task. The NASA TLX methodology 
has become the "gold standard" for measuring subjective workload, as evidenced by approximately 300 research publications in an array of disciplines [13]. The NASA-TLX is a multidimensional instrument, which gives a total score according to size subscales including: mental demand, physical demand, temporal demand, performance, effort and frustration. The validity and reliability of this scale have been previously confirmed [14] [15] [16].

The research described herein sought to address two objectives: (1) provide a detailed description of how technology can be incorporated into a specific construction management course, specifically a course onreading construction drawings, and (2) understand the percieved workload of construction management students when analyzing drawings through three typical modalities: hard copy drawings, digitial drawings viewed on a computer, and digitial drawings viewed on a tablet device (i.e., an iPad). A detailed research methodology is provided, along with the research results. Research conclusions, limitations, and future research are also discussed.

\section{Research methodology}

The study utilized an action research approach to collect student performance and perception data in an introductory plan-reading course at Auburn University. Action research is the process of systematic inquiry by teachers in their own classrooms for the purposes of understanding and improving the quality or effectiveness of the learning environment for students [17]. Action research methods have been widely used for collecting student information for the improvement of teaching and learning [18] [19] [20] [21]. The authors decided to employ an action research approach since one objective of the study focused on the learning impacts of navigating and extracting information from drawings using different modalities. The existing construct of the class was used to deliver the different modalities and record the student's performance and perceptions of the experience. This study was broken into three different phases over the course of three weeks, as shown in Figure 1.

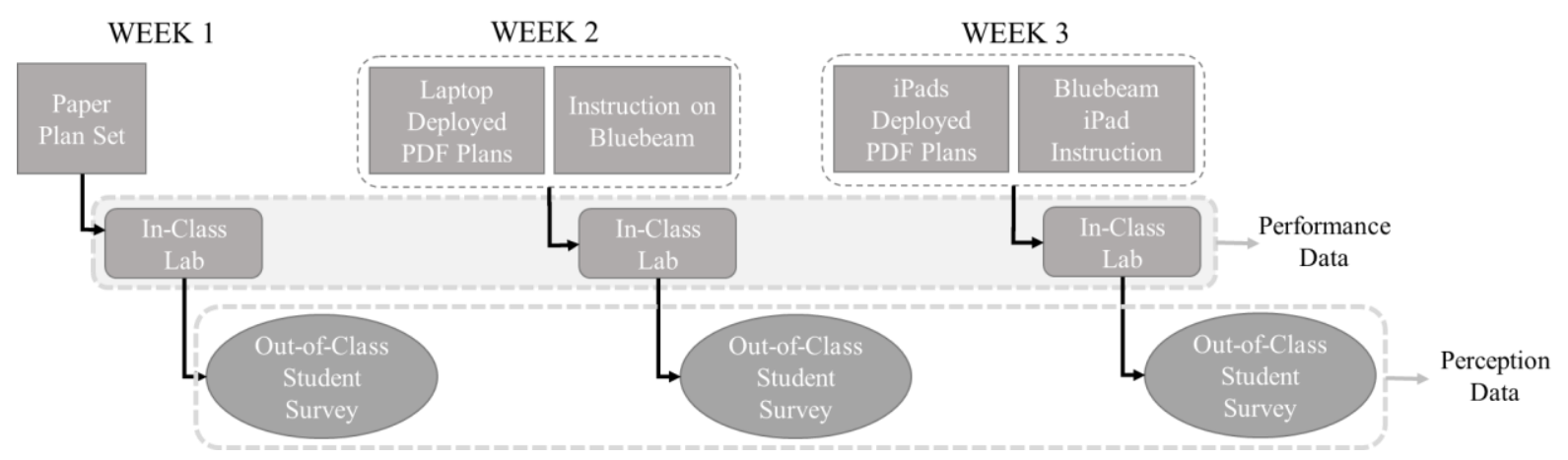

Figure 1. Research phases

Each week of the study focused on isolating the student experience to a different modality for analyzing the drawings to discern information based on a set of predetermined questions. In week one, full-size paper sets of the drawings were analyzed to answer the questions in that week's lab, as shown in Figure 1. In week two, an electronic version of plans was provided to the students in a PDF file format. Students were required to use their own laptop computers and Bluebeam ${ }^{\circledR}$ as the software for viewing and navigation of the plan set. Bluebeam Studio® was 
used as the vehicle for housing the plan set. It served as an easy mechanism for providing the students access to the plan set while eliminating potential issues associated with downloading the plans to their computers. The students each participated in a class session ahead of the lab to have the software installed on their computers and complete an introductory training tutorial on the use of Bluebeam ${ }^{\circledR}$. The preparatory session alleviated any issues with students not being familiar with Bluebeam ${ }^{\circledR}$ software, and ensuring that the software was properly loaded on their computers.

In week three the students were provided with iPads as the tool for navigating the drawings. Once again, Bluebeam ${ }^{\circledR}$ was the software used (in this case the associated iPad app) and Bluebeam Studio ${ }^{\circledR}$ was used as the deployment mechanism for the drawing set. The subsequent use of Bluebeam ${ }^{\circledR}$ and Bluebeam Studio ${ }^{\circledR}$ helped focus the independent variable to the iPad and not the software platform, as students were already familiar with the platform. Each student participated in an introductory training session to introduce them to the iPads, go through login and navigation items, and make sure the software was installed, working, and they could access the plan set, similar to the training session completed during week two.

Measures were taken to control common independent variables associated with approach, as a means to improve the validity of the results. A single plan set that the participants were already using in the class was used for all three phases of the study. This consistency eliminated the concern of skewing results due to student differences in familiarity of the plan set. Also, the study was conducted during regular class meeting times in the regularly scheduled classroom to mitigate any issues related to the classroom environment.

Student performance data was captured through the use of in-class labs. Labs were the typical construct of the course and involved students attempting to answer a series of questions in which the answers had to be located within the plan set. Student scores of correct responses were calculated after each lab was completed. The student's assessment of their perceived workloads of each modality were collected via an online survey developed in Qualtrics. The survey itself (see Appendix A) was structured to match the NASA-TLX methodology, where six separate factors (mental demand, physical demand, temporal demand, performance, effort, frustration) are scored based on a 20-point scale.

A link to the anonymous TLX surveys, with informed consent, was distributed to the students at the end of each week. Students were allowed to complete the survey outside of class, so that they did not feel pressure to complete the questionnaire in the classroom setting. However, they were asked to complete the survey no later than the start of the next week's class, when the new modality would be introduced. The survey was developed to collect descriptive and demographic information before the participants completed the NASA-TLX portion of the questionnaire. The questionnaire was constructed exactly the same for each of the three weeks with the only change being the NASA-TLX task and the tailoring of each of the NASA-TLX questions to incorporate the specific modality being assessed. 


\section{Research results}

The accessible population for this study included 23 students enrolled in an introductory planreading course at Auburn University. Because the study took an action-research approach, the only reason for lack of participation from week to week would have been due to student absence during the lab session for each week. If a student was present for the regular class lab session, they participated in completing the lab using the modality required for that particular week. For each of the three weeks, all 23 students participated in the regularly-scheduled three-hour lab session. The most prevalent academic classification selected of the participants was Sophomore, undergraduate.

The participant group included three females and twenty male students. Out of the total participant responses, 15 participants answered yes to the question "Have you had an internship or work experience with a construction related firm?" The amount of time, expressed in months, of the internships and/or work experience for these 15 students was equally distributed as follows: five students had 1-3 months, five students had 4-6 months, and five had 9-12 months. None of the participants had over 12 months of internship and/or work experience. Eight students had no previous internship or work experience.

Survey respondents were asked two questions ahead of completing the NASA-TLX portion of the survey related to their perceived proficiency of navigating construction drawings and specifications, and their perceived competency of utilizing technology for visualization, manipulation, and documentation of digital construction drawings to retrieve $\&$ communicate project information. Both of these questions are course learning objectives and tie to American Council for Construction Education (ACCE) student learning outcomes. Each of these questions was scored on a Likert scale of 1-5, the results of which are summarized in Tables 1 and 2. As shown, the majority of respondents stated that they felt they were sufficiently proficient to navigate construction drawings and specifications after completing the lab exercise utilizing paper drawings, and no students felt that they were completely proficient. This trend changed after iPads were introduced. Just over 70 percent of respondents stated that they perceived themselves to be between sufficient proficient and completely proficient, and four percent of respondents perceived that they were completely proficient. Moreover, 65 percent of respondents felt that they were somewhat competent regarding the utilization of technology for visualization, manipulation, and documentation of digital construction drawings to retrieve \& communicate project information after completing the lab exercise utilizing paper drawings. Just under 80 percent of respondents were somewhat competent after iPads were introduced.

\section{Table 1: Student perspectives on document navigation competency}

\begin{tabular}{|l|c|c|c|}
\hline How proficient are you at navigating construction drawings and specifications to efficiently retrieve information? \\
\hline & Paper & Laptop & iPad \\
\hline (1) Not at all proficient & $0.00 \%$ & $0.00 \%$ & $0.00 \%$ \\
\hline (2) & $4.35 \%$ & $0.00 \%$ & $4.17 \%$ \\
\hline (3) Sufficiently proficient & $56.52 \%$ & $30.43 \%$ & $20.83 \%$ \\
\hline (4) & $39.13 \%$ & $60.87 \%$ & $70.83 \%$ \\
\hline (5) Completely proficient & $0.00 \%$ & $4.35 \%$ & $4.17 \%$ \\
\hline
\end{tabular}


Table 2: Student perspectives on application of technology competency

\begin{tabular}{|c|c|c|c|}
\hline $\begin{array}{l}\text { Rate your competency level at this point in the semeste } \\
\text { visualization, manipulation, and documentation of digit } \\
\text { project information. }\end{array}$ & $\begin{array}{l}\text { lls to eff } \\
\text { awings t }\end{array}$ & $\begin{array}{l}\text { y use tec } \\
\text { eve \& co }\end{array}$ & $\begin{array}{l}\text { y for } \\
\text { cate }\end{array}$ \\
\hline & Paper & Laptop & iPad \\
\hline (1) Incompetent & $0.00 \%$ & $0.00 \%$ & $0.00 \%$ \\
\hline (2) Somewhat incompetent & $8.70 \%$ & $0.00 \%$ & $0.00 \%$ \\
\hline (3) Neither competent nor incompetent & $17.39 \%$ & $17.39 \%$ & $8.33 \%$ \\
\hline (4) Somewhat competent & $65.22 \%$ & $65.22 \%$ & $79.17 \%$ \\
\hline (5) Extremely competent & $8.70 \%$ & $13.04 \%$ & $12.50 \%$ \\
\hline
\end{tabular}

The results of the student's performance on the weekly lab assignments is provided below in Table 3. As shown, the lab exercise where iPads were utilized by the students to analyze the drawings exhibited the highest average score of any of the three modalities, at nearly $90 \%$ accuracy. It should be noted that the lab assignment during week 2 included an optional extra credit question allowing for a possible max score of $105 \%$.

Table 3. Results of student performance on lab assignments

\begin{tabular}{|c|c|c|c|c|c|c|}
\hline Modality & Topic area & High score & Low score & $\begin{array}{c}\text { Average } \\
\text { score }\end{array}$ & $\begin{array}{c}\text { Number of } \\
\text { questions }\end{array}$ & $\begin{array}{c}\text { Number of } \\
\text { respondents }\end{array}$ \\
\hline $\begin{array}{c}\text { Hard-copy } \\
\text { drawings }\end{array}$ & $\begin{array}{c}\text { Structural } \\
\text { foundations }\end{array}$ & $91 \%$ & $68 \%$ & $81.64 \%$ & 36 & 23 \\
\hline $\begin{array}{c}\text { Electronic } \\
\text { drawings } \\
\text { analyzed on } \\
\text { computers }\end{array}$ & $\begin{array}{c}\text { Steel } \\
\text { superstructure }\end{array}$ & $102 \%$ & $50 \%$ & $85.55 \%$ & 29 & 23 \\
\hline $\begin{array}{c}\text { Electronic } \\
\text { drawings } \\
\text { analyzed on } \\
\text { iPads }\end{array}$ & $\begin{array}{c}\text { Load-bearing } \\
\text { masonry }\end{array}$ & $97 \%$ & $76 \%$ & $89.77 \%$ & 28 & 23 \\
\hline
\end{tabular}

The results of the NASA-TLX portion of the survey are provided in Table 4. As shown, regarding mental demand (how mentally demanding was the task), respondents felt that laptop computers had the highest mental demand, while iPads had the lowest. These results were the same regarding physical demand (how physically demanding was the task) and temporal demand (how hurried or rushed was the pace of the task). Concerning performance (how successful they felt they were in accomplishing the task) iPads had the highest average score, and laptops had the lowest. Relating to effort (how hard they felt they had to work to achieve their level of performance) paper drawings showed the highest average, while iPads had the lowest average. Lastly, regarding frustration (how insecure, discouraged, irritated, and annoyed they felt during the task) laptop computers had the highest average level of frustrations, while iPads had the lowest. 
Table 4: Results of NASA-TLX survey

\begin{tabular}{|r|c|c|c|c|c|c|}
\hline & $\begin{array}{c}\text { Mental } \\
\text { Demand }\end{array}$ & $\begin{array}{c}\text { Physical } \\
\text { Demand }\end{array}$ & $\begin{array}{c}\text { Temporal } \\
\text { Demand }\end{array}$ & Performance & Effort & Frustration \\
\hline Paper drawings \\
\hline \# of responses & 22 & 21 & 22 & 21 & 23 & 21 \\
\hline Average & 10.64 & 6.58 & 7.89 & 15.89 & 13.42 & 7.79 \\
\hline Laptop computers \\
\hline \# of responses & 22 & 20 & 19 & 21 & 20 & 20 \\
\hline Average & 11.23 & 7.55 & 9.63 & 15.29 & 11.70 & 9.45 \\
\hline iPads & & & \\
\hline \# of responses & 21 & 21 & 21 & 22 & 21 & 19 \\
\hline Average & 9.24 & 6.00 & 7.43 & 16.05 & 10.62 & 7.42 \\
\hline
\end{tabular}

\section{Discussion of results}

Qualitative feedback collected from instructor observations over the three weeks indicate that most students preferred the electronic version of the drawings when using the iPads. Students indicated they liked this modality for the ease of use in scrolling through the different plan sheets and zooming in and out on each sheet. Comments from the students about the iPad user interface, "using the hand gestures on the iPads just seems natural" and "the iPad is like using a large version of my phone and that makes it easier" suggest that the modality is more intuitive to their generation. Comments when using the laptops, "the process of moving from one sheet to another is difficult", "why can't I just scroll my mouse wheel and get the sheets to change", "using my trackpad on my laptop is too difficult", and "I try to do things on my touch screen like I would my phone and it doesn't work - that is frustrating to me" also supported this notion. When discussing the experience with the students at the end of the three weeks there were differing opinions about the preferred modality. Some indicated preference for having the full set of paper plans in front of them, stating "I just like have the physical sheets to be able to flip through" and "having the entire sheet right in front of me at all times makes me more comfortable". However, some of those same students commented on the benefit of the iPad being able to "zoom in really close to see a detail that is harder to read on the paper set". When comparing the electronic plan version on the laptops versus the iPads, responses anecdotally favored the iPads for navigating and viewing the drawings. However, a couple students commented that they could see the benefit of the computer version when trying to do other tasks in Bluebeam such as measuring, quantifying, and marking-up various things on the plans.

The qualitative instructor feedback was supported by the results of the in-class lab assignments and the NASA-TLX survey. Students overall had higher average scores on the iPad assignment as compared to the paper drawings and laptop-based exercises. Furthermore, the mental, physical, and temporal aspects of using an iPad to analyze construction drawings showed to be lower than when similar tasks were completed with paper drawings and laptops. Moreover, students felt that they performed better with less effort and frustration when using the iPads. Lastly, as shown in Tables 2 and 3, students perceived higher proficiency of navigating construction drawings and specifications, and higher competency of utilizing technology for 
visualization, manipulation, and documentation of digital construction drawings to retrieve \& communicate project information after completing the lab where iPads were utilized.

\section{Conclusions, limitations, and future research}

This action research case study sought to address two objectives: (1) provide a detailed description of how technology can be incorporated into a specific construction management course, specifically a course on reading construction drawings, and (2) understand the percieved workload of construction management students when analyzing blueprints through three typical modalities: hard copy drawings, digitial drawings viewed on a computer, and digitial drawings viewed on a tablet device (i.e., an iPad). Students participated in a three-week long study that involved learning how to read construction plans using paper documents, electronic plans available on a computer, and electronic plans available on a touch-sensitive mobile device.

The authors have laid-out a clear methodology for incorporating different technologies into an undergraduate plan reading class, the results of which showed that students preferred and felt most comfortable when utilizing an iPad to analyze construction documents. This research aimed to inform instructors of the changes in student performance when using different modalities in a plan reading course. The results of this study can, therefore, be used to help faculty that are interested in using technology but are uncertain of the impact that it will have on the student's performance.

Overall, the collected performance data from the labs indicate there is no major difference in performance from one modality to another. Oftentimes, when students are exposed to a new learning approach in the classroom, there is a tendency for performance to suffer. It is encouraging that the incorporation of laptops and iPads not only failed to yield these results, performance was actually indicated to be higher. While the results suggest that student performance increased when moving from paper to iPad, these results should be taken lightly as there are a number of other variables that could be contributing to these results. Future studies should be done to more rigorously explore any statistically significant differences in performance between the modalities.

While results support the notion that students generally like using iPads to navigate and view drawings, further research should be done on the performance impact. One study from the University of Oklahoma [5] looked at student performance on the basis of accuracy and time. While the case study presented in this paper considered some level of student accuracy, time was not a variable of consideration. As well, measures were not implemented during this study to control for external factors that might influence student performance, such as help from other students. However, statistical rigor is not typically common in the action-research approach. Overall, the authors feel the outcomes of the study were beneficial. Good information was obtained on student perceptions of the different modalities and a look at any easily noticeable differences in performance. At the very least, this provides data that other faculty can use when considering similar type implementations into their classes. The approach presented in this study could be duplicated by any instructor currently teaching a similar type class or even other classes involving construction documents. 
Lack of statistical rigor aside, the authors believe that the results from this case study support results from the Oklahoma study, encouraging continued research in this area on a larger scale. Future consideration should include a more controlled experimental approach focusing on performance outcomes measuring accuracy and time over a larger sample that allows for generalizing the results. The authors plan to take the outcomes from this case study and the Oklahoma study to develop a larger study in this area. Additionally, this study did not involve any statistical analysis to explore the potential of significant differences in performance between modalities. Future research should also include this element of analysis.

\section{$\underline{\text { References }}$}

[1] Galanek, J. D., Gierdowski, D. C., \& Brooks, D. C. (2018). "ECAR Study of Undergraduate Students and Information." Educause Center for Analysis and Research.

[2] Pilgrim, J., Bledsoe, C., \& Reily, S. (2012). "New technologies in the classroom." Delta Kappa Gamma Bulletin, 78(4).

[3] JBKnowledge. (2017). The 6th Annual Construction Technology Report, accessed on 1/6/2019: https://jbknowledge.com/2018-construction-technology-report-survey

[4] Kim, J. (2018) "A Study to Investigate Using Mobile Devices in the Construction Management Classroom as Rationalized by the Needs of Industry", 2018 Creative Construction Conference, Ljubljana, Slovenia.

[5] Reyes, M. D., CPC, S. G., Perrenoud, A. J., \& Goldman, J. A. (2015). "Teaching plan reading to construction students: The effect of using tablet computers." 51st Annual International Conference Associated Schools of Construction (ASC), College Station, Texas.

[6] Shirazi, A., \& Behzadan, A. H. (2014). "Design and assessment of a mobile augmented reality-based information delivery tool for construction and civil engineering curriculum." Journal of Professional Issues in Engineering Education and Practice, 141(3), 04014012.

[7] Azhar, S., Kim, J., Salman, A. (2018) "Implementing Virtual Reality and Mixed Reality Technologies in Construction Education: Students' Perceptions and Lessons Learned", 11th Annual International Conference of Education, Research and Innovation, Seville, Spain.

[8] Cristia, J., Ibarrarán, P., Cueto, S., Santiago, A., \& Severín, E. (2012). "Technology and child development: Evidence from the one laptop per child program."

[9] Redden, L., Collins, W., \& Kim, J. (2017). "Integration of construction mobile technologies into construction management curriculum: a case study." 2017 Creative Construction Conference, Primosten, Croatia.

[10] Collins, W., Redden, L., \& Kim, J. (2018). "Leveraging mobile applications to promote ACCE student learning outcomes." Associated Schools of Construction Annual Conference 2018, Minneapolis, Minnesota.

[11] Collins, W., Kim, J., Redden, L., \& Herlong, J. (2019). "Mobile device utilization in classes by faculty of ASC-member and ACCE-accredited construction programs." Associated Schools of Construction Annual Conference. 2019, Denver, Colorado. (Accepted for publication). 
[12] Cline, R., and Davis, K. (2013). "Using mobile technology in a construction management "hands-on" laboratory." $120^{\text {th }}$ American Society for Engineering Education (ASEE) Annual Conference \& Exposition. Atlanta, Georgia.

[13] National Aeronautics and Space Administration (NASA) Task-Load Index website, accessed on 1/27/2019 at https://humansystems.arc.nasa.gov/groups/TLX/

[14] Mohammadi M, Mazloumi A, Kazemi Z, Zeraati H. "Evaluation of Mental Workload among ICU Ward's Nurses.” Health Promotion Perspectives, 2015; 5(4): 280-287.

[15] Rubio S, Diaz E, Martin J, Puente JM. "Evaluation of subjective mental workload: A comparison of SWAT, NASA-TLX, and workload profile methods." Applied Psychology, 2004; 53:61-86.

[16] Trujillo, A. "Evaluation of Electronic Formats of the NASA Task Load Index." National Aeronautics and Space Administration (NASA) Langley Research Center. Hampton, VA. 2011. Report: NASA/TM-2011-217166, L-19919, NF1676L-11282. Retrieved on 1/15/2019: https://ntrs.nasa.gov/search.jsp?R=20110014454

[17] C. Mertler, (2012) Action research: Improving schools and empowering educators. (3rd ed.). Thousand Oaks, CA: Sage.

[18] S. Ganguly, "Action Research to Improve the Communication Skills of Undergraduate Students," IUP Journal of Soft Skills, vol. 11, (3), pp. 62-71, 2017.

[19] C. J. Cronin and J. Lowes, "Embedding experiential learning in HE sport coaching courses: An action research study," Journal of Hospitality, Leisure, Sport \& Tourism Education, vol. 18, pp. 1-8, 2016.

[20] C. Farias, P. A. Hastie, and I. Mesquita, "Towards a more equitable and inclusive learning environment in Sport Education: results of an action research-based intervention," pp. 1-17, 2015.

[21] P. Gibbs et al., "Literature review on the use of action research in higher education," Educational Action Research, vol. 25, no. 1, pp. 3-22, 2017. 


\section{Appendix A: Survey}

Construction Documents Coursel Learning Mediums (Laptop Implementation)

Welcome! We are interested in understanding your learning of plan reading through various mediums. You will be presented with information relevant to this topic and asked to answer some questions about it. Please be assured that your responses will be kept completely confidential. We will not ask for you to give us your name or contact information in this survey. The questionnaire should take you around 5 minutes to complete. Your participation in this questionnaire is voluntary. You have the right to withdraw at any point during the study, for any reason, and without any prejudice. If you would like to contact the Principal Investigator in the study to discuss this research, please e-mail Dr. Wesley Collins [wac0020@auburn.edu]. By clicking the button below, you acknowledge that your participation in the study is voluntary, and that you are aware that you may choose to terminate your participation in the study at any time and for any reason. Please note that this survey will be best displayed on a laptop or desktop computer. Some features may be less compatible for use on a mobile device.

Please indicate your age group.

1 Younger than 19

220 - 25 years

326 - 30 years

431 and older

Please indicate your gender.

1 Male

2 Female

What classification best describes your academic year?

1 Freshman, undergraduate

2 Sophomore, undergraduate

3 Junior, undergraduate

4 Senior, undergraduate

5 Graduate

Have you had an internship or work experience with a construction related firm?

1 Yes

2 No 
How much intern or work experience have you had, in terms of months? Express your response as months - for example, 2 years $=24$ months. Insert 0 for none.

How proficient are you at navigating construction drawings and specifications to efficiently retrieve information?

5 - Completely proficient

4

3 -Sufficiently proficient

2

1 -Not proficient at all

Rate your competency level at this point in the semester: Apply basic skills to effectively use technology for visualization, manipulation, and documentation of digital construction drawings to retrieve \& communicate project information.

Extremely competent Somewhat competent

Neither competent nor incompetent

Somewhat incompetent

Extremely incompetent 
The following set of questions asks you to evaluate workload demand on you this week in the course while you performed a specific 'TASK.' This task is defined below. You are asked to rate your score on an interval scale ranging from low (1) to high (20).

TASK DEFINITION: learning in the class this week while using your laptop to view the drawings

Mental Demand / Task: Learning while viewing drawings on laptop How mentally demanding was the task?

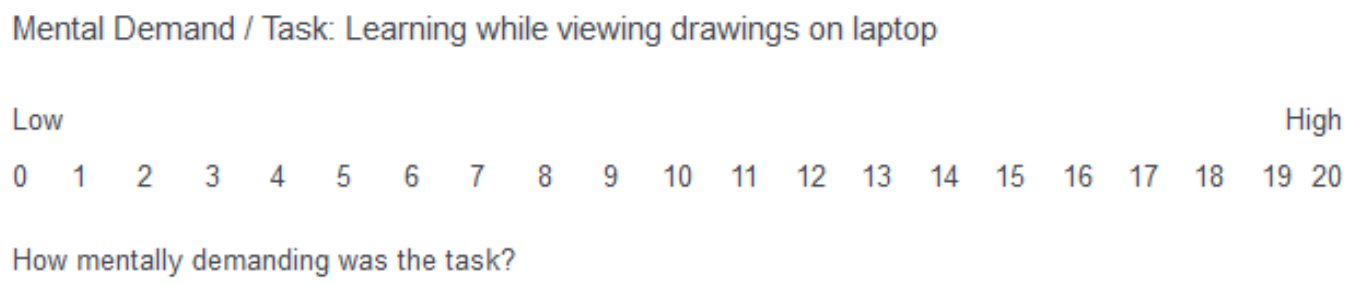




\section{Performance / Task: Learning while viewing drawings on laptop}

How successful were you in accomplishing what you were asked to do?

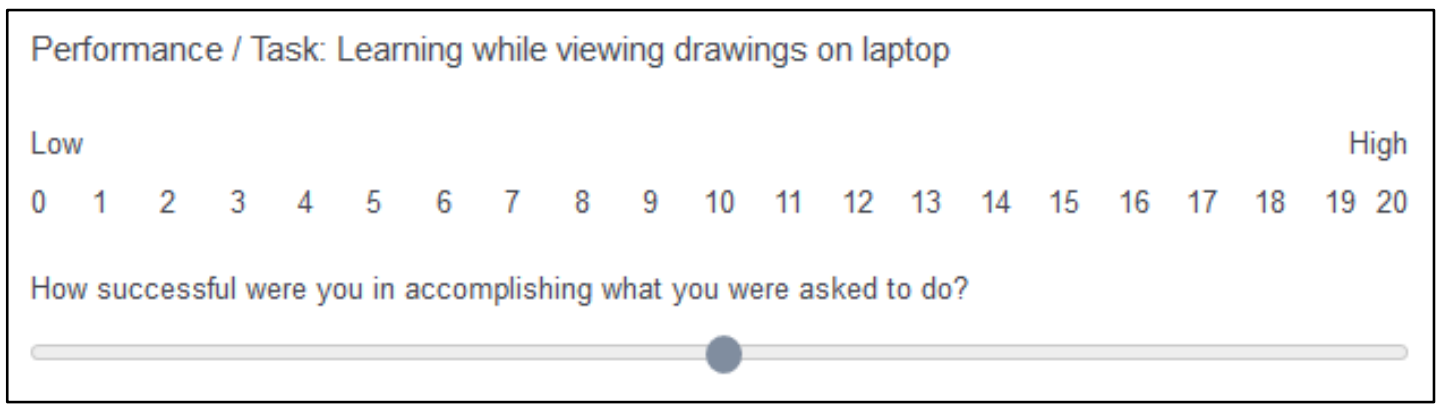

\section{Effort / Task: Learning while viewing drawings on laptop}

How hard did you have to work to accomplish your level of performance?

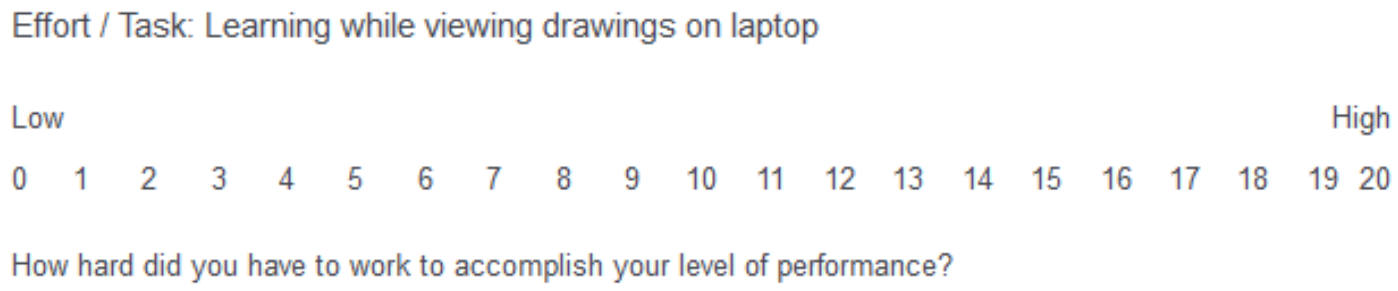

\section{Frustration / Task: Learning while viewing drawings on laptop}

How hurried or rushed was the pace of the task?

Frustration / Task: Learning while viewing drawings on laptop
Low
$\begin{array}{llllllllllllllllllllll}0 & 1 & 2 & 3 & 4 & 5 & 6 & 7 & 8 & 9 & 10 & 11 & 12 & 13 & 14 & 15 & 16 & 17 & 18 & 19 & 20 \\ \text { How insecure, discouraged, irritated, stressed, and annoyed were you? }\end{array}$

